\title{
The Impact of Ambient Environmental Exposures to Microbial Products on Asthma Outcomes from Birth to Childhood
}

\author{
Evin Howard ${ }^{1} \cdot$ Vwaire Orhurhu $^{2} \cdot$ Lisa Huang $^{3} \cdot$ Barbara Guthrie $^{1} \cdot$ Wanda Phipatanakul ${ }^{4}$
}

Published online: 28 November 2019

(C) Springer Science+Business Media, LLC, part of Springer Nature 2019

\begin{abstract}
Purpose of Review Asthma is a chronic respiratory condition with increasing domestic and worldwide prevalence that burdens individuals and the healthcare system with high costs associated with long-term treatments and acute emergency room (ER) visits. It can be triggered by ambient microbes, including bacteria, viruses, and fungi. In this review, we examine the outcomes of asthma patients in relation to environmental exposures to ambient microbe products, focusing on whether exposure leads to asthma development from birth to childhood and if particular microbes are associated with worsened asthma exacerbations.

Recent Findings Bacterial endotoxin is more prominent in homes with pets and may cause cytokine cascades that lead to asthma exacerbation. However, some studies have demonstrated a protective effect with early exposure. Patients with positive Aspergillus skin testing are more prone to moderate-severe or severe-uncontrolled asthma. Fungal sensitization is also associated with earlier onset of asthma and demonstrates a dose-dependent relationship of symptom severity and duration. Among viruses, rhinovirus has the greatest association with decreased lung function, severe asthma, and asthma-related hospital admissions. Distribution of microbial products and associated asthma symptoms depends on the geographical climate. Genetic variations among individuals also mitigate the effects of microbial products on asthma development and symptom severity.

Summary Microbial products of bacteria, fungi, and viruses are associated with the development of asthma, more severe asthma symptoms, and worse outcomes. However, some early exposure studies have also demonstrated a protective effect. Bacterial and fungal products are related to decreased lung function and earlier onset of asthma. Viral products are related to asthma-associated hospital admissions; and the climate and patient genetics can also temper or intensify the relationships between microbial products, asthma development, and asthma symptom severity. Further research should focus on the effects of early microbe exposure and its interaction with human immune systems and asthma-related outcomes.
\end{abstract}

Keywords Early microbial exposure $\cdot$ Asthma outcomes $\cdot$ Allergen sensitivity $\cdot$ Bacteria $\cdot$ Fungi $\cdot$ Virus

This article is part of the Topical Collection on Allergies and the Environment

Wanda Phipatanakul

Wanda.Phipatanakul@childrens.harvard.edu

1 Bouvé College of Health Sciences, Graduate School of Nursing, Northeastern University, Boston, MA, USA

2 Department of Anesthesia, Critical Care, \& Pain Medicine, Harvard Medical School, Massachusetts General Hospital, Boston, MA, USA

3 Department of Anesthesia, Critical Care, \& Pain Medicine, Harvard Medical School, Beth Israel Deaconess Medical Center, Boston, MA, USA

4 Division of Asthma, Allergy, \& Immunology, Harvard Medical School, Children's Hospital Boston, Boston, MA, USA

\section{Introduction}

Every day, 10 people in the USA die from asthma [1]. In 2017 alone, there were 3,564 asthma-related deaths [1,2]. Within the USA, the prevalence of asthma is 1 in 13 people, producing annual economic costs of over $\$ 81.9$ billion, related to missed school and work, medical costs, and asthma-related mortality [1-3]. Ambient microbes have been shown to trigger asthma attacks [4-6]. The most common microbes are bacteria, viruses, and fungi [7]. Though the literature has clearly demonstrated that microbes and allergens can trigger asthma exacerbations, controversy still remains whether or not microbes promote the development of asthma with early-life exposure or if they have a preventative effect against asthma symptoms in an individual with established disease [4-6]. Many longitudinal studies have demonstrated that early 
exposure to ambient microbial products increases the risk of the development of asthma [8•, 9, 10, 11•]. Whereas, other studies, particularly related to human contact with animal microbes, have shown protective effects against the development of asthma [8•, 12, 13]. With over 1.8 million asthma-related ER visits each year, which may be potentiated by exposure to various ambient microbial products in the environment, earlylife exposure to microbial products and its effect on the respiratory system later in childhood warrants further investigation $[2,6,14,15]$.

\section{Purpose}

The purpose of this literature review was to specifically examine asthma outcomes related to environmental exposures to microbial products, pertaining to endotoxin from bacteria$(1,3)$ - $\beta$-D-glucan and ergosterol from fungus, and common viruses associated with worsening asthma morbidity (rhinovirus, respiratory syncytial virus (RSV), enterovirus, and the influenza virus) during infancy, and to assess the risk of asthma development later in childhood [15-18] (see Table 1).

While other reviews have focused on common routes of exposure and the concentration of microbial products (endotoxin, fungal spores, virus, etc.) in urban vs. suburban regions $[19,20]$, this review investigates if the exposure to microbial products during infancy leads to the development of asthma during childhood, and whether particular microbes have a higher severity for triggering asthma exacerbations over others. Primary questions for this review consisted of the following: What microbes are associated with asthma severity and outcomes? What microbial products are known for triggering asthma symptoms and/or exacerbations? Does the exposure of microbial products in the environment lead to the development of asthma?

For this review, we selected original manuscripts in English, published in peer-review journals on the basis of bacterial, fungal, and viral products within the environmental matrix with children exposed to these microbial products. Thus, we selected articles examining health outcomes for the

Table 1 Microbes and associated microbial products related to selected studies

\begin{tabular}{ll}
\hline Microbe & Microbial product/ type \\
\hline Bacteria & Endotoxin \\
Fungi & $(1,3)-\beta$-D-glucan \\
& Ergosterol \\
Virus & Human rhinovirus (HRV) \\
& Respiratory syncytial virus (RSV) \\
& Enterovirus \\
& Influenza virus \\
\hline
\end{tabular}

development of asthma related to microbial product exposure during the time of infancy until childhood. However, we also highlighted factors in the literature that contribute to microbial exposure and their effect on asthma for people with an established diagnosis of asthma. Only journal articles within the last 5 years were chosen; however, there were no restrictions pertaining to specific populations or geographical locations.

Exclusion criteria consisted of animal studies, investigative procedures using only in vitro methods, studies not translated into English, articles focusing on the measurement of microbial products without their effect on asthma outcomes, and articles not assessing microbial exposure from the time of infancy. With this thought process in mind, the following word criteria was applied using PubMed as the primary search engine:

("Asthma"[Mesh] OR asthma[tiab] OR asthmatic*[tiab]) AND ("Microbiota"[Mesh] OR "Bacteria"[Mesh] OR “Antigens, Bacterial"[Mesh] OR “Bacterial Toxins”[Mesh] OR “Enterotoxins"[Mesh] OR "Fungi"[Mesh] OR "Mycotoxins"[Mesh] OR "Viruses"[Mesh] OR bacteria[tiab] OR bacterial[tiab] OR endotoxin*[tiab] OR enterotoxin*[tiab] OR fungal[tiab] OR fungi[tiab] OR fungus[tiab] OR lipopolysaccharides[tiab] OR microbial [tiab] OR microbiome*[tiab] OR microbiota*[tiab] OR mold[tiab] OR molds[tiab] OR mycotoxin*[tiab] OR peptidoglycan[tiab] OR staph[tiab] OR Staphylococcus[tiab] OR teichoic acid*[tiab] OR virus*[tiab] OR viral[tiab]) NOT ("Animals"[Mesh] NOT "Humans”[Mesh]) AND (“2014/01/01”[PDat] : “2019/12/ 31'[PDat]) AND English[lang].

\section{Results}

The search returned a total of 2999 articles. After the removal of 2924 studies, consisting of reviews, duplicates, mouse studies, and irrelevant articles to asthma health outcomes, this then left 76 studies. 65 Studies were pertaining to adults, which left a total of $N=11$ studies (see Fig. 1).

\section{Characteristics of Included Studies}

The majority of the studies had a prospective cohort design (9/11), while the other two studies were retrospective cohort designs. Environmental sampling consisted of different locations in participants' homes (living room, kitchen, bedroom, mattress), outside air, and settled dust in classrooms. All of the studies included examined asthma health outcomes related to ambient exposure to bacterial, fungal, and viral microbial products. Considering bacterial products and asthma outcomes, the literature has discussed endotoxin, $\beta$-glucan, and lipopolysaccharide (LPS). Of these microbial products, 


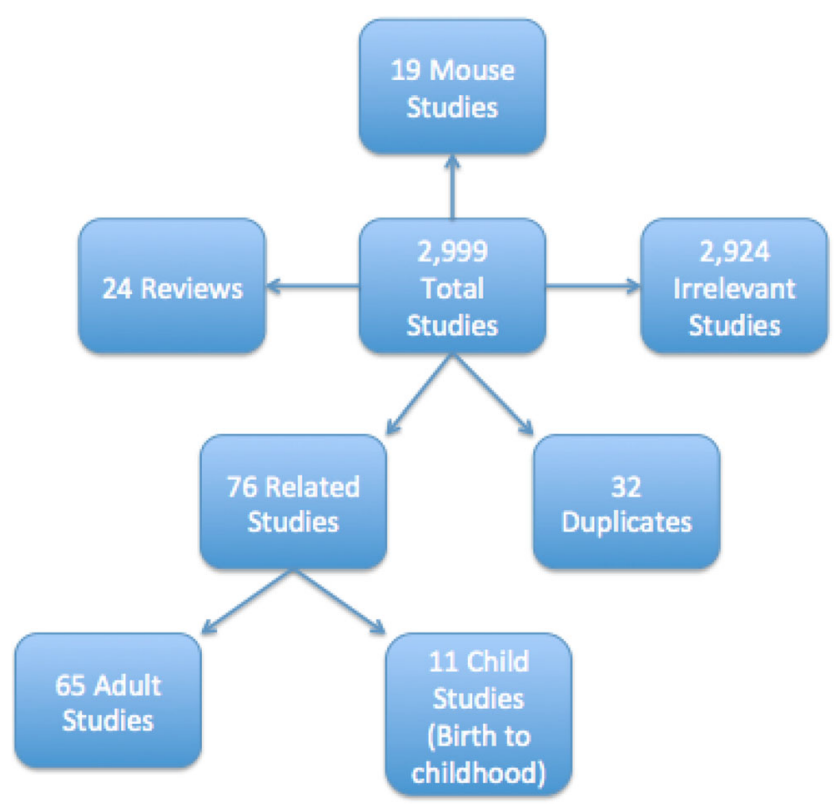

Fig. 1 Selection criteria for related studies

endotoxin has been well established with asthma outcomes [5, $14,21,22]$.

\section{Endotoxin}

When bacteria are destroyed or lysed, LPS is dispersed into the environment or blood as endotoxin, which can lead to a cascade of inflammatory cytokines (IL-6, IL-12, IL1 $\beta$, and TNF- $\alpha$ ) and exacerbation of asthma symptoms [22, 23]. The main route of contact to endotoxin is via inhalation, which has been demonstrated in multiple studies [5, 14, 21, 22]. Of the 11 studies selected for review, there were two that specifically discussed endotoxin exposure from infancy [8•, 24••] (see Table 2). Tischer et al. conducted a prospective longitudinal study examining whether early exposure to microbial products in dust was associated with allergy and asthma later in childhood for children in suburban areas using the following three birth cohort studies for children born between 1996 and 1999: Prevention and Incidence of Asthma and Mite Allergy (PIAMA) from the Netherlands, Infancia y Medio Ambiente- Childhood and Environment (INMA) from Spain, and Influence of Life-Style factors (LISAplus) on the development of the Immune System and Allergies in East and West Germany [8•]. The researchers collected dust samples from living room floors shortly after children were born and found that high endotoxin levels were positively associated with asthma at 6 years of age in the PIAMA cohort (adjusted $\mathrm{OR}=1.96 ; 95 \% \mathrm{CI}(1.07-3.58))$, but there was no association with the LISAplus cohort [8•]. However, there was an inverse relationship between endotoxin and asthma in the INMA cohort from Spain at age $10(\mathrm{OR}=0.39 ; 95 \% \mathrm{CI}(0.16-0.94))$. The INMA cohort from Spain had the highest number of pets in terms of dogs and cats with exposure from 0 to 1 year of age, compared to the other groups [8•]. Whereas, in a study conducted by O'Connor et al. [24••], dust samples were collected from children's mattresses, bedroom floors, and living room floors; and showed no association between endotoxin nor the fungal membrane lipid ergosterol in the development of asthma with exposure from birth to 7 years of age. Previous research has shown that endotoxin levels tend to be higher in homes with a pet such as a cat or dog in addition to homes of families that are low-income and/or may be in community projects that contain cockroaches $[5,31]$. Similar results were seen in children by a study conducted by Mendy et al. [32] who found that overall for people who had a cat or dog, endotoxin levels were higher in the household with a pet and was associated with wheeze $(\mathrm{OR}=1.30 ; 95 \% \mathrm{CI}(1.04-1.62))$ but not with asthma [32]. Co-exposure with dog and cat allergens modified the association with asthma, increasing the risk when exposed to endotoxin $(\mathrm{OR}=2.00 ; 95 \% \mathrm{CI}(1.04-3.83))$ [32]. However, the O'Connor et al. [24••] study found that exposure of a pet cat or dog from the time of infancy decreased the chances of developing asthma later in childhood $(\mathrm{OR}=0.71,95 \% \mathrm{CI}(0.51-$ $1.00)$ and $\mathrm{OR}=0.78,95 \% \mathrm{CI}(0.56-1.09)$, respectively). For people with an established asthma diagnosis, regardless of allergen sensitization, Thorne et al. [5] demonstrated that endotoxin exposure is associated with wheeze with exercise, office or ER visits, and use of prescription medication for wheezing [5]. Studies have indicated that lung function and capacity can be decreased due to continuous exposure to endotoxin in patients with atopic asthma $[22,33]$.

Lipopolysaccharide has also been shown to promote eosinophil airway inflammation in patients with asthma despite maintenance treatment with inhaled corticosteroids (ICS) [34].

Besides having a pet, there are other factors that could have contributed to the varying results between the cohorts within the Tischer et al.'s study. The climate also plays a role in the concentration of endotoxin in the surrounding environment $[14,31]$. Researchers have found a positive correlation between $\log _{10}$-endotoxin and current asthma $(\mathrm{OR}=1.56,95 \%$ CI (1.11-2.18), $p=0.046$ ) for hot-humid regions and a higher incidence of exercise-induced wheeze $(\mathrm{OR}=1.48,95 \% \mathrm{CI}$ (1.22-1.80), $p=0.009)$ for subarctic/very cold/cold regions [31]. High levels of endotoxin, regardless of being inside or outside the home environment, are associated with severe asthma [14, 35]. A study conducted in Japan by Khan and colleagues showed that asthma-related visits to the ER for patients 15-years-old or older was highest during the seasons of autumn and spring, when the environmental endotoxin was highest in the air [14]. Oluwole et al. [35] showed that for 7 to 17-year-olds, high concentrations of endotoxin within households, including mattresses, are associated with an elevated risk of moderate or severe asthma (adjusted OR $=11.40$, 95\% CI (1.45-89.43)). Tischer et al. [8•] also supported these 


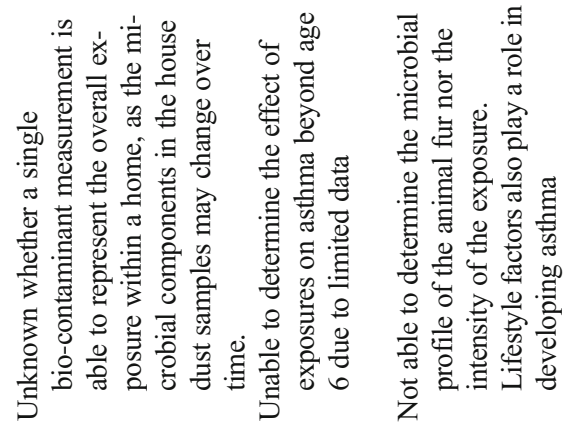

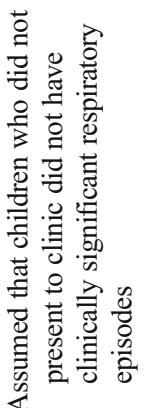

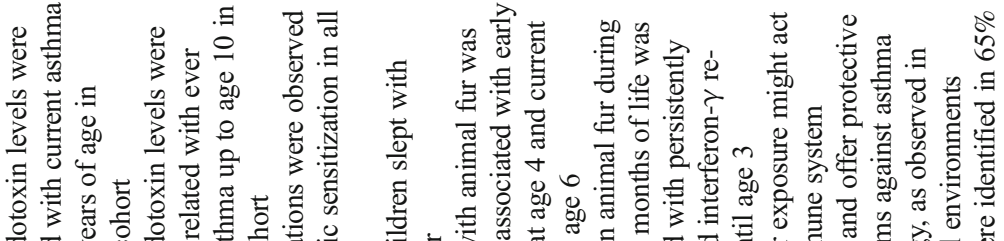

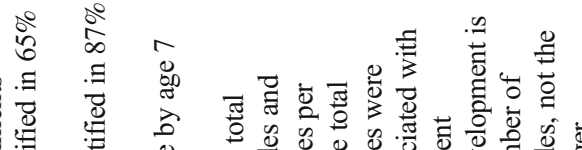

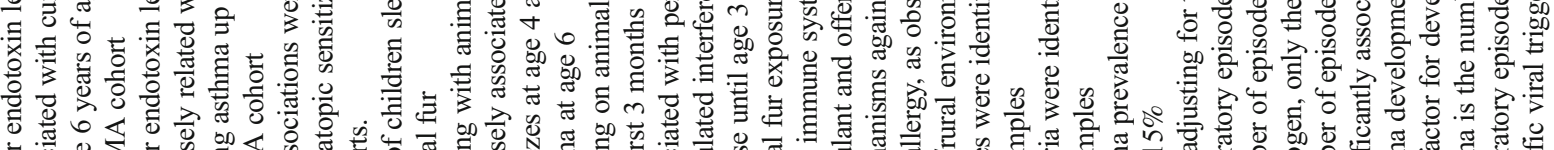

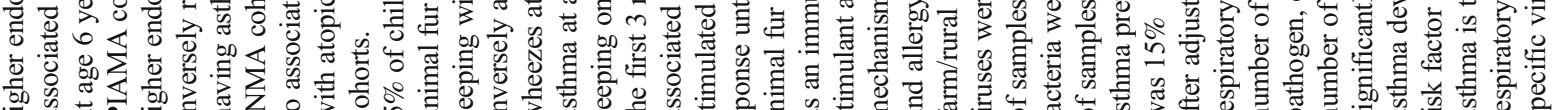

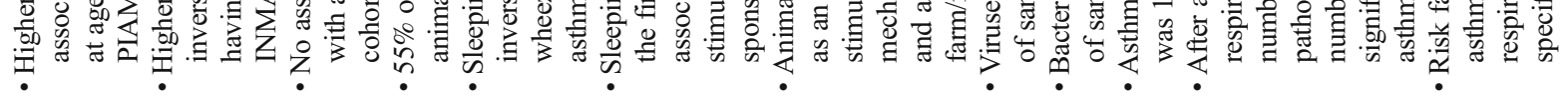

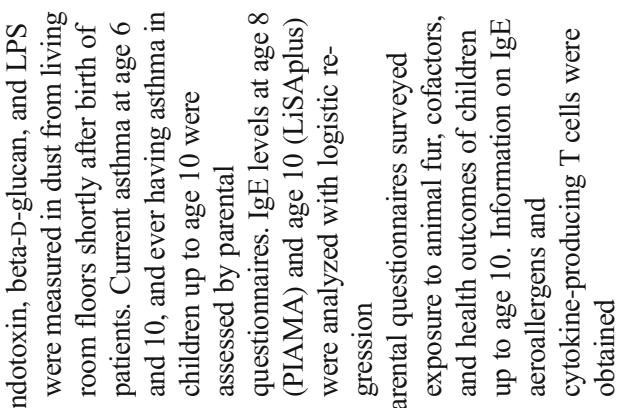
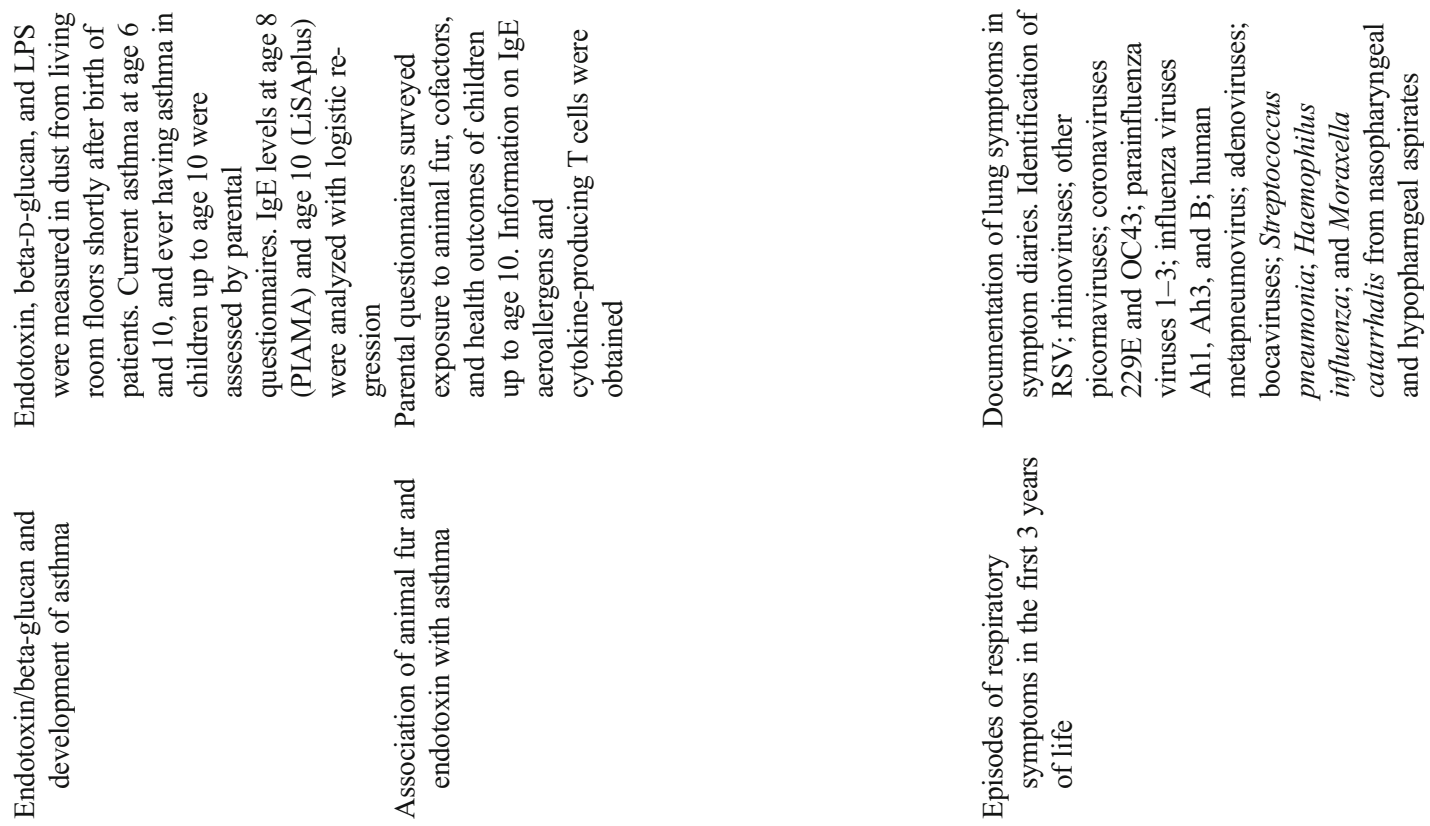

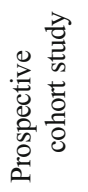

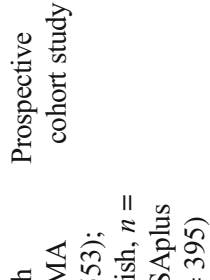

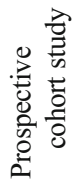
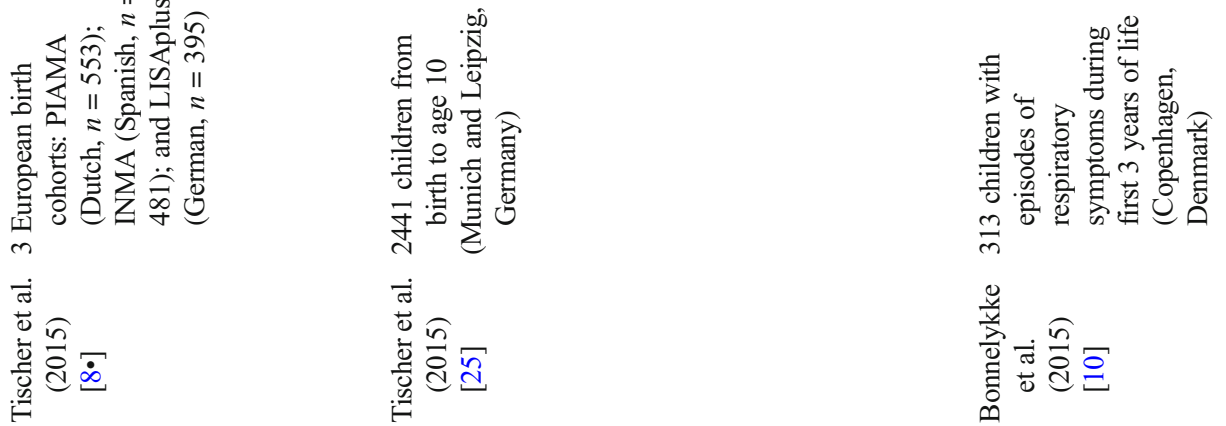


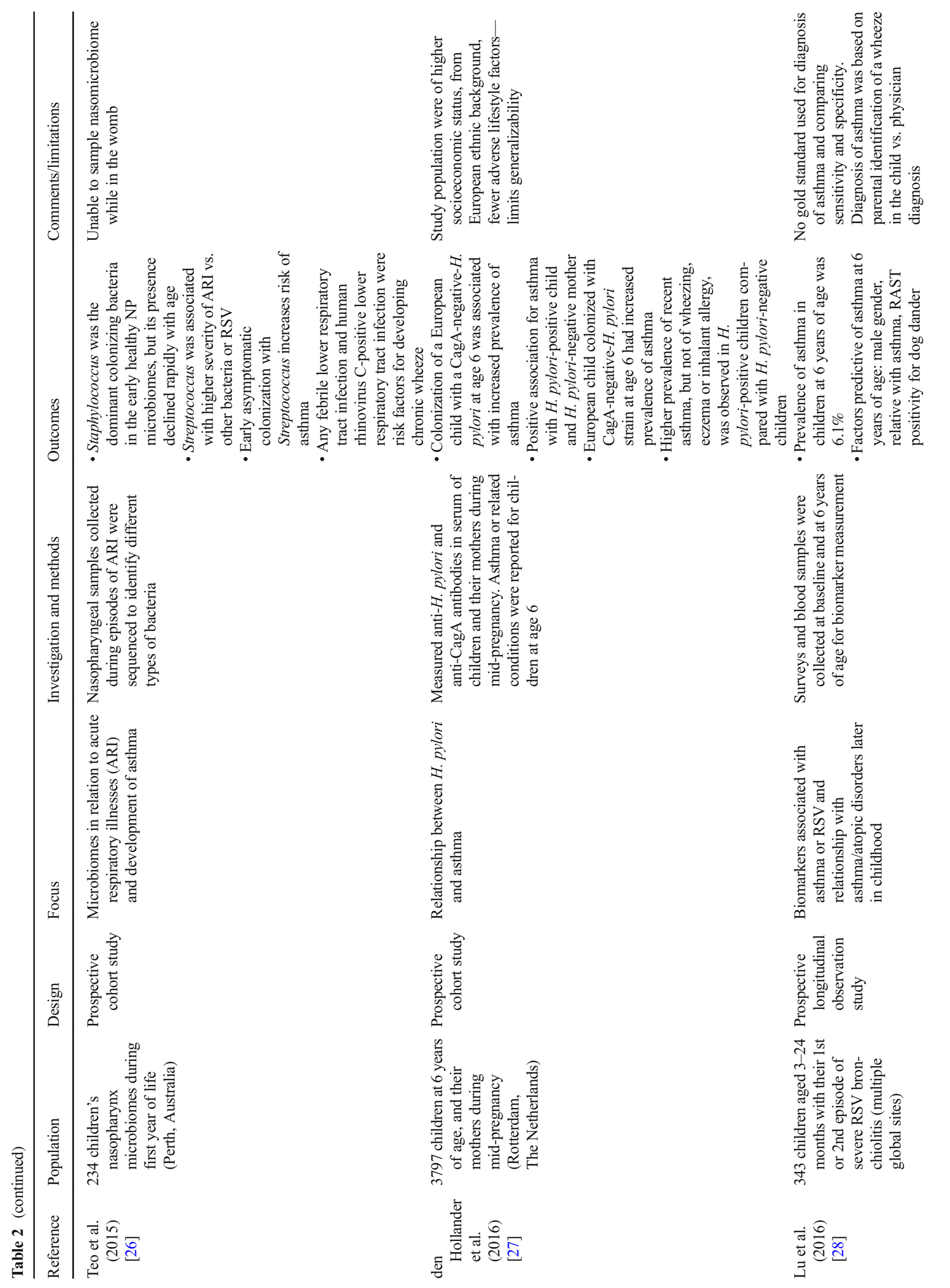



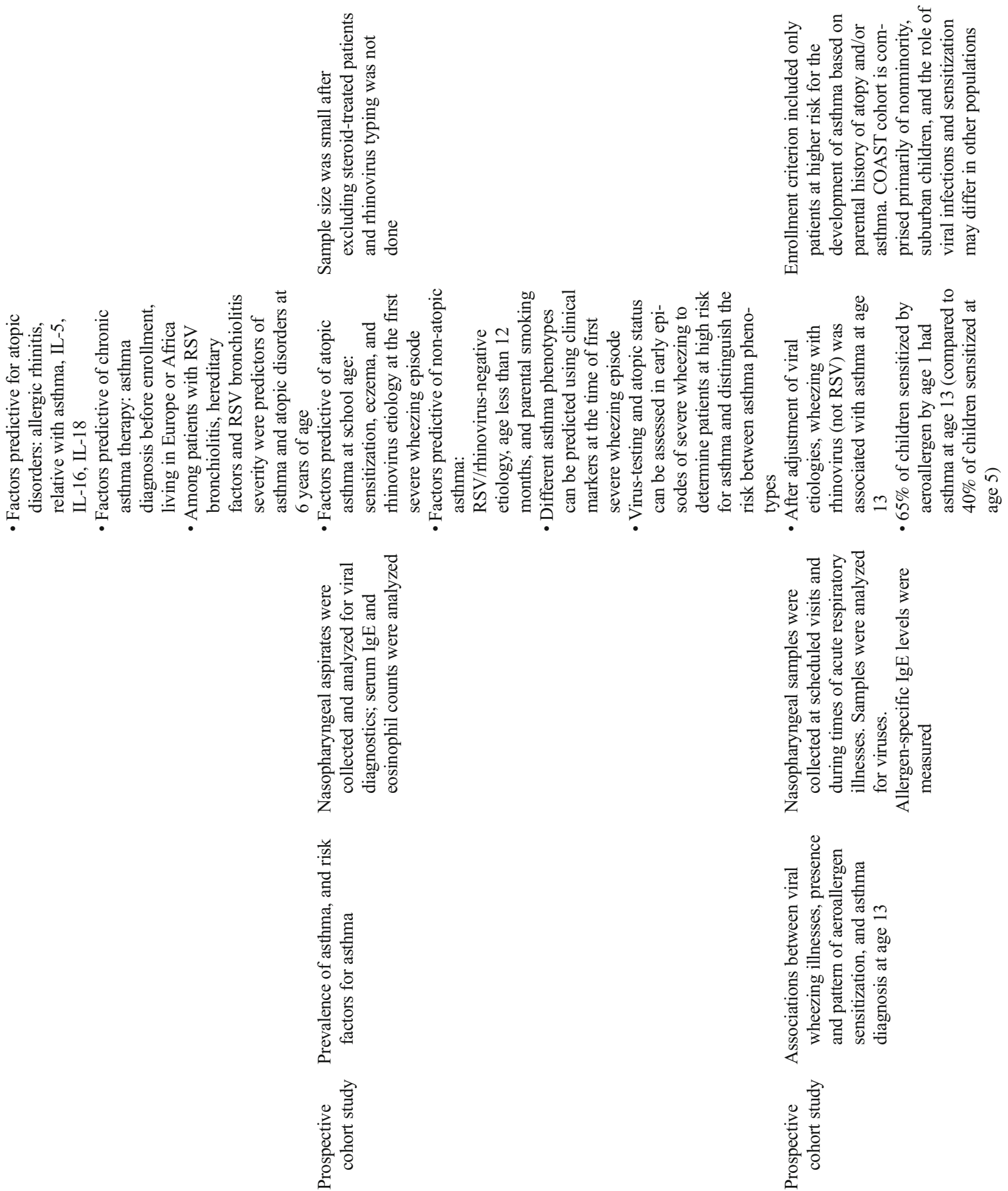

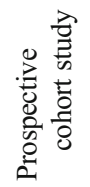

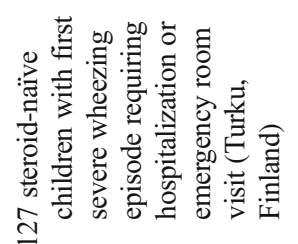

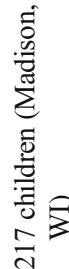

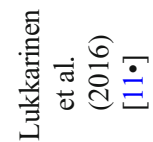

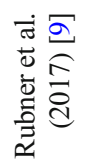




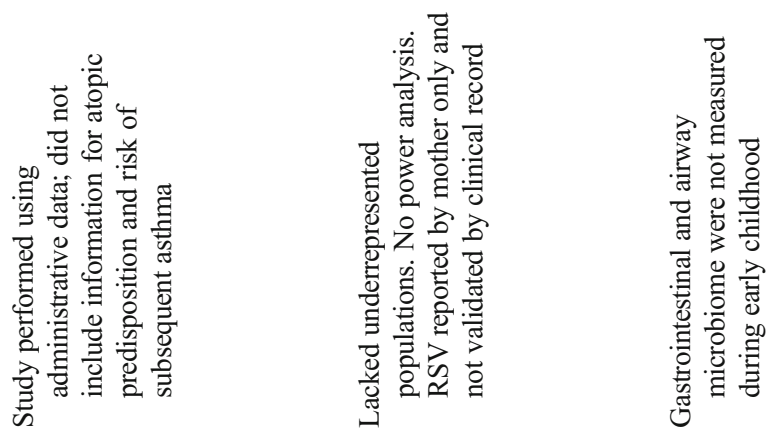

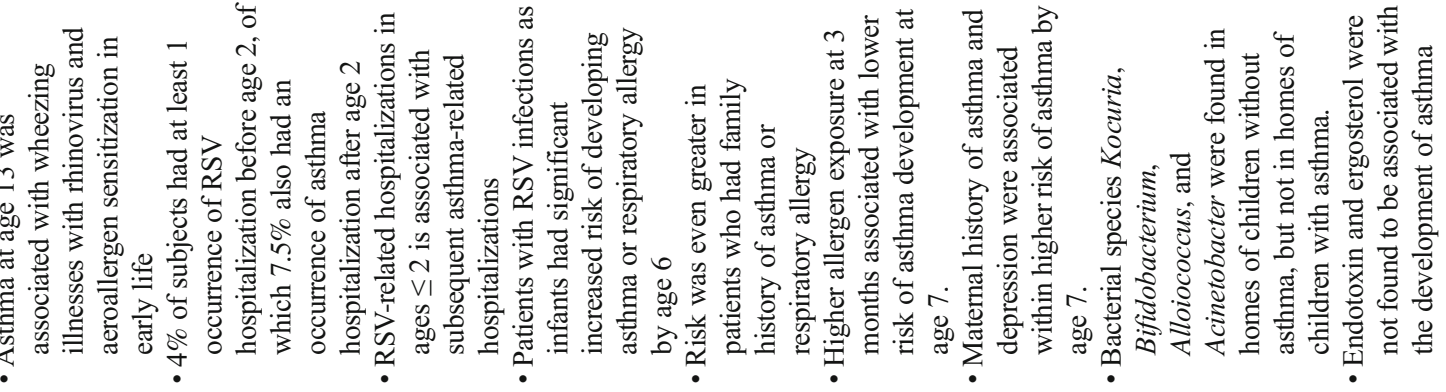
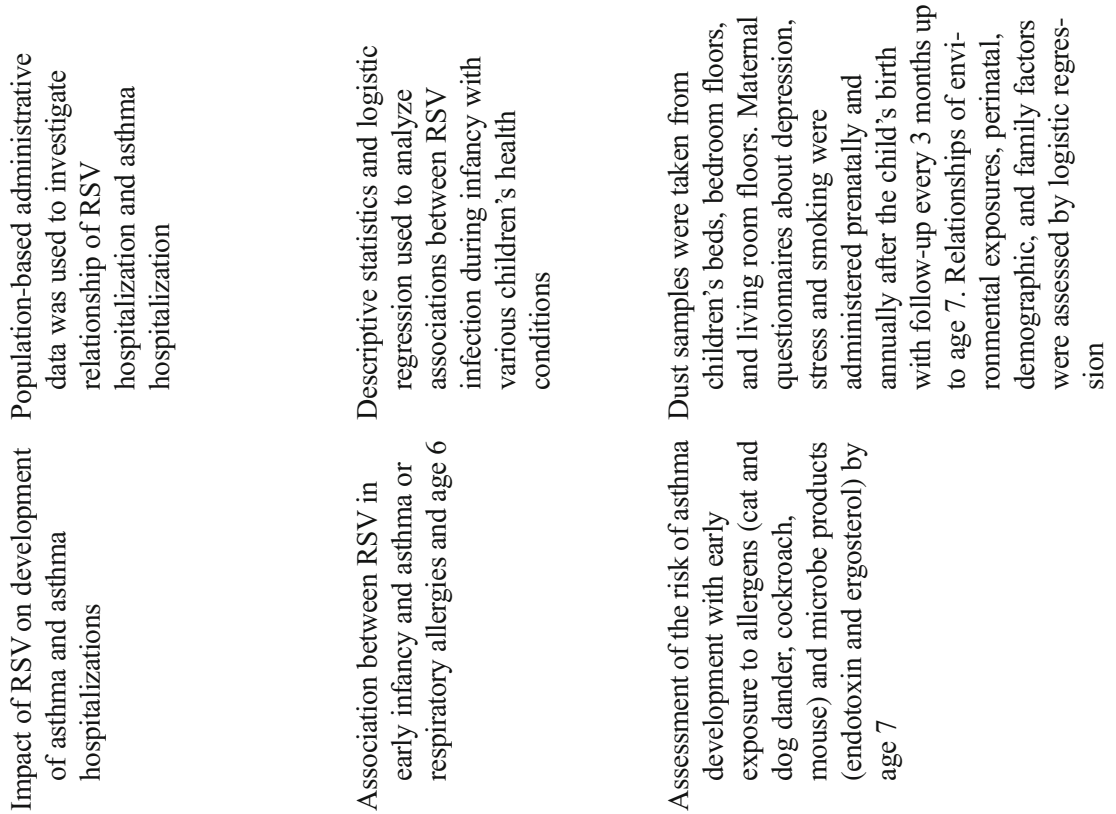

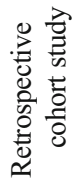
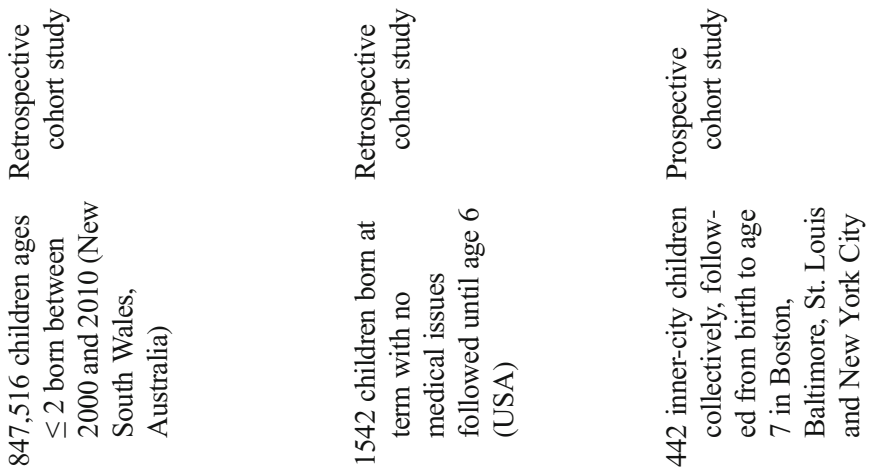

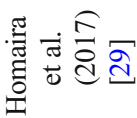

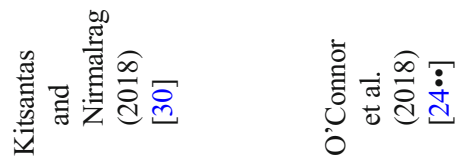


results for children from infancy to 6 years of age. In addition, these findings are also in accordance with previous investigations in the early 2000s [36-39].

Non-environmental patient characteristics can also impact the development or severity of asthma. Mendy et al.'s [40] study determined that the combination of high levels of endotoxin exposure and low vitamin D levels are associated with an asthma diagnosis or recurrent wheeze $(\mathrm{OR}=1.88$, 95\% CI (1.33-2.66), $p=0.02)$, current asthma ( $\mathrm{OR}=1.97$, 95\% CI $(1.09-2.23), p=0.03)$, wheeze over the last 12 months $(\mathrm{OR}=1.72,95 \% \mathrm{CI}(1.10-3.7), p=0.002)$, and recurrent wheeze $(\mathrm{OR}=1.97,95 \% \mathrm{CI}(1.0-4.0), p<0.001)$ [40]. Nevertheless, this study was conducted in adults and the effect from infancy to childhood, regarding vitamin D levels in combination with endotoxin exposure, would need to be assessed. No studies on fungal spore exposure were found for the time period from birth to childhood to assess the development of asthma.

\section{Fungi}

Fungal exposure plays a vital role in asthma health outcomes. For the Tischer et al.'s [8•] study, no correlations were found between the fungal product $(1,3)-\beta$-D-glucan and the PIAMA and LISAplus studies [8•]. $(1,3)-\beta$-D-glucan was not evaluated for in the INMA cohort study [8•]. Sensitization to fungal antigens is a key component to understanding asthma severity. Chopra and colleagues showed that asthma patients with skin reactivity to the Aspergillus skin test (AST) had more cases of moderate and severe asthma versus nonreactive AST patients (98.6\% vs. $3.2 \%, p<0.001)$ in a cohort of 282 adult asthma patients over a 1-year period. Sensitization to Aspergillus has been found to have a more significant impact on asthma outcomes compared to other species of fungus [41, 42]. For instance, Vincent et al. [41] demonstrated that adult asthma patients who were sensitized to Penicillium chrysogenum, Cladosporium cladosporiodes, Cladosporium sphaerospermum, or Penicillium brevicompactum were comparable to the control group in having a lower risk of severe asthma compared with the Aspergillus fumigatus group $(15.6 \%$ vs. $50 \%, \mathrm{OR}=5.4,95 \%$ CI $(1.0-29.06), p=0.059)$ [41]. Masaki and colleagues' study in Japan implicates a different species; their study investigated sensitization to Candida and found that out of 124 adults with asthma, more people had sensitization to Candida than Aspergillus (16 vs. $11 \%$ ) [6]. The researchers also found that fungal sensitization leads to a higher rate of early-onset asthma $(<16$ years of age) compared to those without sensitization $(45 \%$ vs. $25 \%)$ and sensitization increases with age $[6,43]$. However, further investigation is needed to examine early exposure of various fungal species during infancy and its effect on the development of asthma during childhood.
The fungal genus Alternaria has also provided more insight into fungal sensitization and asthma outcomes. Recently, Baxi and colleagues conducted a study in 37 inner-city schools in New England with school-aged children with asthma and observed that children sensitized to Alternaria had an association with asthma symptom days $(\mathrm{OR}=3.61,95 \%$ CI $(1.34-9.76), p=0.01)$; however, this did not apply to children not sensitized to Alternaria $(\mathrm{OR}=$ $1.04,95 \%$ CI $(0.72-1.49), p=0.85)$ [44]. Researchers found that asthmatic children who were sensitized to Alternaria and exposed to high levels had 3.2 more symptom days per 2week period when compared to asthmatic and sensitized children exposed to lower levels of Alternaria. This suggests a dose-dependent relationship between mold exposure and asthma severity [44]. This finding is supported by Oluwole et al. [45], who demonstrated that high mold levels in children's play areas are associated with current asthma (adjusted OR = 3.0, 95\% CI (1.11-8.0)). Furthermore, additional studies have demonstrated that sensitization to Alternaria increases with higher mold concentration exposure and may lead to a risk of hospitalization, especially in the urban setting [46-49].

Fungal exposure also impacts lung function [41]. Asthma patients with sensitization to Aspergillus fumigatus have been found to have higher total serum IgE levels and an increased degree of broncho-obstruction (as measured by $\mathrm{FEV}_{1} / \mathrm{FVC}$ ), compared to asthmatic patients without sensitization $[41,50]$. The impact of fungal exposure on lung function has been evaluated in adults; however, this has not been thoroughly evaluated in infants and young children.

The fungal product $(1,3)-\beta$-D-glucan has been shown to have a low association with severe asthma $(\mathrm{OR}=0.55,95 \%$ CI $(0.24-1.26), p=0.003)$ in children [51, 52]. Ergosterol has also demonstrated a low affinity for the development of asthma [52]. However, exposure to fungal spores has been shown by multiple studies in adults to be associated with asthma exacerbations; yet, there are very few studies involving children [53-55]. In a study analyzing the fungal microbiome in exhaled breath condensate (EBC) of patients with asthma in Italy, Carpagnano et al. [53] found that in 47 adults with asthma, $94 \%$ of the people were colonized in the EBC by Cladodosporium species, $21 \%$ by Alternaria, and $24 \%$ by Penicillium species [53]. Fungal colonization tended to be higher in asthmatics with severe and uncontrolled asthma with sensitization to fungal species such as Alternaria [53-55]. The differing levels of fungal species, with Cladosporium being the most abundant, and Alternaria and Penicillium in lower quantities, was also found in Manitoba, Canada, by Polyzoi and Polyzois, examining mold within the bedrooms and basements of 3424 school-aged children [56]. Cladosporium was the most common mold found in homes $(98.2 \%$ of bedrooms and $97.8 \%$ of basements), followed by Alternaria ( $82.4 \%$ of bedrooms and $77 \%$ of basements), and Penicillium (35.4\% of bedrooms and $48.8 \%$ of basements). In addition, visible mold 
in bedrooms and basements in participants' homes were associated with persistent asthma and colds $(16.8 \%, p<0.0001)$. Other fungal studies conducted in Europe, Canada, and Australia have also found similar results [45, 57, 58]. Viral exposure also plays a critical role in the development of asthma and asthma morbidity $[9,11 \bullet]$.

\section{Viruses}

\section{Rhinovirus}

Two studies were found that were conducted on early-life exposure to rhinovirus and asthma outcomes: One by Rubner et al. [9] and another by Lukkarinen et al. [11•]. Rubner et al. [9] conducted a prospective cohort study with 217 children, examining early-life rhinovirus exposure from birth to 13 years of age. The researchers observed that wheezing with rhinovirus was associated with asthma at age 13 (OR $=3.3,95 \% \mathrm{CI}(1.5-7.1), p=0.02)$ and sensitization to allergens increased with age [9]. $\mathrm{FEV}_{1} \%$ predicted has also been shown to be lower in asthmatic patients admitted to the hospital with an asthma exacerbation with concurrent rhinovirus infection, compared to children with asthma admitted for an exacerbation but negative for rhinovirus [29, 59].

Lukkarinen et al. [11•] performed a 7 -year long prospective cohort study following 127 Finnish children from birth to 7 years of age and found that the risk factors for atopic asthma at study entry were sensitization to common allergens (dust, mold, etc.), and wheezing with rhinovirus infection (aOR $4.8, p<0.014)[11 \cdot]$.

Zheng et al. [15] conducted one of the numerous studies that demonstrated that human rhinovirus (HRV) was the most common viral microbe to induce an asthma exacerbation in children [60-62]. Zheng and colleagues collected data from 143 inpatient children with asthma exacerbations, 131 outpatients, including 88 patients with asthma exacerbations, and 43 controls with stable asthma [15]. Researchers tested for common viruses including HRV, respiratory syncytial virus (RSV), parainfluenza virus type 3 (PIV3), influenza virus (IFV), human bocavirus $\left(\mathrm{HBOV}_{1}\right)$, atadenovirus (ADV), human coronavirus (HCOV), and hepatitis E virus. Of all the viruses, HRV was the most prominent among inpatients with severe asthma exacerbations at $50.3 \%$ and HCOV was the least at $0 \%$ [15]. The researchers found three variants of the HRV: HRV-A, HRV-B, and HRV-C, with HRV-C being the most virulent for severe asthma exacerbations [15]. Other studies conducted in Japan, France, and Australia have also identified rhinovirus as the most common viral culprit for asthma exacerbations [28,60-62]. White blood cells and neutrophil counts were significantly higher in patients with all HRV variants versus those who were negative for HRV $(12.38 \pm 5.13$ vs. $10.77 \pm 4.87$ and $64.70 \pm 20.27$ vs. 56.44 \pm 21.95 , respectively) [15].
Thymic stromal lymphopoietin (TSLP), a cytokine that impacts T cell maturation, also plays a role in asthma severity in patients with viral illnesses. It has been demonstrated to have a positive outcome on patients during viral infections in patients with asthma [60]. Bjerregaard et al. [60] performed a study in Australia with 44 virus-positive adolescent and adult patients (including rhinovirus, human coronavirus, parainfluenza virus, and human metapneumovirus) and 44 controls. The researchers found that patients with TSLP expression had lower levels of sputum eosinophils, lower fractional exhaled nitric oxide, higher blood neutrophils, lower asthma control questionnaire scores, and higher $\mathrm{FEV}_{1}$ in comparison to patients with low TSLP expression levels [60]. Again, these types of studies are rare for examining variances in lung function and asthma development from birth to childhood.

\section{Respiratory Syncytial Virus}

In total, four studies were found on respiratory syncytial virus (RSV) that followed children from birth to childhood for the development of asthma [10, 28-30]. Two of the RSV studies showed that males from infancy to childhood have a high tendency of developing asthma after an infection, compared to females $[28,29]$ (see Table 2). Two out of the four studies were retrospective cohort studies and the other two were prospective cohort studies [10, 28-30]. One of the retrospective studies showed that peak time for RSV-related hospitalizations was during autumn [29]. The RSV studies showed a high risk for asthma with RSV infection and that the cytokines IL-6, IL$1 \beta$, and IL- 8 are elevated during infection, which leads to respiratory inflammation [10, 28]. Kitsantas et al. [30] conducted a 6-year long study from birth to 6 years of age, examining the risk of the development of asthma by 6 years with early exposure of RSV infection during infancy. Results showed that exposure to RSV did increase the risk of asthma by age $6(\mathrm{OR}=$ $1.99,95 \%$ CI (1.06-3.74)). However, children who had a parent with a history of asthma posed a higher risk for childhood asthma by age $6(\mathrm{OR}=3.86,95 \% \mathrm{CI}(2.61-5.71))$ [30]. A maternal history of asthma has also been demonstrated by O'Connor et al. [24••] to increase the likelihood of asthma in childhood by age $7(\mathrm{OR}=1.79,95 \% \mathrm{CI}(1.18-2.74))$.

Similar to what was discussed about fungi, asthma patients can also be colonized by viruses. Nguyen-Thi-Dieu et al. [63] conducted a cohort study in Hanoi, Vietnam, on 115 hospitalized children under the age of 15 with a diagnosis of asthma exacerbation and a control group of healthy children under the age of 15. Patients underwent a clinical examination, blood analysis for a cytokine profile, pediatric asthma score (PAS) for severity of asthma exacerbation, and nasopharyngeal aspirates to determine viral infection using real-time polymerase chain reaction (PCR). Of the 115 children diagnosed with an asthma exacerbation, there were $18.2 \%$ with a mild PAS, $37.4 \%$ with a moderate PAS, and $44 \%$ with a severe PAS 
[63]. Nguyen-Thi-Dieu and colleagues found that $54.8 \%$ of the asthmatic children were positive for HRV [63]. The high number of asthma patients with a severe PAS score (44\%) was associated with a high number of children diagnosed with HRV [63]. The researchers also found that the percentage of leukocytes in asthmatic children with HRV was significantly higher, compared to children without HRV (76.2\% vs. 59.6\%, $p<0.05$ ) [63]. No enterovirus longitudinal studies from birth to childhood were available, assessing asthma development; however, studies have been done in children with a diagnosis of asthma [64].

\section{Enterovirus}

Smith-Norowitz et al. [64] studied patients in Ireland, examining the levels of $\operatorname{IgE}$ and IgM antibodies ( $\mathrm{Ab}$ ) for enterovirus 71 with a mix of 77 children and adolescents, and found that asthmatic children have higher IgE Ab levels, compared to non-asthmatic children, who have higher IgM levels of $\mathrm{Ab}$ $(p<0.001)$. The levels of enterovirus IgE Ab were shown to increase with age especially among the asthmatic group [64].

Another study analyzed data on a 16-year longitudinal study with 36,935 children from infancy to 18 years of age in Taiwan and found that children were diagnosed with asthma within 2.77 years after an enterovirus infection [16]. There was also a higher incidence of asthma associated with enterovirus infection ( $\mathrm{HR}=1.65,95 \% \mathrm{CI}(1.60-1.71), p<0.0001)$ [16]. Overall, the literature suggests that the rate of hospitalization due to enterovirus infection is low and does not increase asthma severity or length of hospital stay for asthma-related admissions $[65,66]$.

\section{Influenza Virus}

The influenza virus is a major cause of acute exacerbation of bronchial asthma (AEBA); however, rhinovirus has still been shown to be the number one viral cause of asthma exacerbations [67]. Yoshi et al. and other researchers have shown that obtaining the flu vaccine reduces AEBA morbidity significantly when compared to individuals who are unvaccinated for the influenza virus $(20.5 \%$ vs. $0 \%), p=0.047[67,68]$. Influenza can worsen asthma morbidity; however, it has yet to be determined if there is a relationship pertaining to the development of asthma in association with an influenza infection [69]. Recent studies have found that certain bacteria play a role in preventative effects against the development of asthma.

\section{Bacteria}

\section{Helicobacter pylori}

Den Hollander et al. [27] performed a population-based prospective cohort study of pregnant women and their children in
Rotterdam, Netherlands, and followed the children from pregnancy to 6 years of age for evaluation of asthma. Colonization of a European child with a cytotoxin-associated protein A (CagA)-negative-Helicobacter pylori (H. pylori) strain at age 6 was associated with an increased prevalence of asthma overall $(\mathrm{OR}=2.11,95 \% \mathrm{CI}(1.23-3.60))$ but was different for European children $(\mathrm{OR}=3.64,95 \% \mathrm{CI}(1.97-6.73))$ and significantly less for non-European children $(\mathrm{OR}=0.52,95 \% \mathrm{CI}$ $(0.14-1.89))\left[11^{\bullet}\right]$. There are also common bacteria within the environmental matrix that have been shown to have an effect on the development of asthma in children.

\section{Staphylococcus}

Teo et al. [26] found that early childhood nasopharynx (NP) colonization typically involved Staphylococcus or Corynebacterium, which was later replaced by Moraxella or Alloiococcus. Staphylococcus was the dominant colonizing bacteria in the early healthy NP microbiomes, but its presence declined rapidly with age. These researchers found that early asymptomatic colonization with Streptococcus increased the risk of developing asthma [26]. Most infants were initially colonized with Staphylococcus or Corynebacterium before stable colonization with Alloiococcus or Moraxella [26]. Transient incursions of Streptococcus, Moraxella, or Haemophilus marked virus-associated acute respiratory infections (ARIs) [26]. O'Connor et al. [24••] found supporting results in a study examining early-life exposure to environmental factors, including dust, fungal products, bacterial taxa; cockroach, mouse, and cat allergen; from infancy to 7 years of age. Staphylococcus, Haemophilus (Pasturellaceae), several Sphingomonas species members, and Corynebacterium were among the taxa found in children's homes who had asthma [24.•]. However, for children who did not have asthma, there was a prevalence of Alloiococcus (Aerobacteriaceae), Kocuria (Micrococcaceae), Acinetobacter (Moraxellaceae) species, and Bifidobacterium [24••]. More research is needed to investigate the mechanism of transition of bacteria from one species to another in the infant microbiome and how this may possibly contribute to the development of asthma. In addition to the microbiome, children's genes affect how their bodies will react to their environment.

\section{Genes and Asthma Health Outcomes}

Like most illnesses, symptoms and severity can vary at the individual level based on unique genetic differences. Carnes et al. [22] found that there is a gene-by environment interaction for CD14 variant rs $2569190\left(p_{\text {interaction }}=0.16\right)$ but not for the TLR4 variants rs4986790 and rs4986791. This research is also supported by an older study conducted by Kljaic-Bukvic et al. [70], who found that there are two genetic variants related to CD14 and endotoxin signaling that are highly related 
with asthma exacerbation hospital admissions. For CD14 single nucleotide polymorphism (SNP) rs5744455, carriers of the T-allele in children 5 to 18 years old had a decreased risk of repeated hospital asthma-related admissions, compared to homozygotes for the $\mathrm{C}$-allele $(\mathrm{OR}=0.42,95 \% \mathrm{CI}(0.25-0.88), p$ $=0.01$ ) [70]. C-allele carriers were at lower risk of asthmarelated hospitalizations in comparison with T-allele homozygotes $(\mathrm{OR}=0.59,95 \% \mathrm{CI}(0.38-0.90), p=0.01)$ [70].

A human interleukin 4 receptor alpha chain gene (IL4R) variant that results in a glutamine to arginine substitution at amino acid residue 576 (IL4R $\alpha$-Q576R polymorphism) has previously been associated with asthma diagnosis and severity [71]. Lai et al. [72] have demonstrated that there is a gene-byenvironment interaction between the IL4R $\alpha$-Q576R polymorphism and environmental endotoxin exposure in school-aged children with asthma. Higher classroom endotoxin levels were associated with fewer asthma symptoms for children with the $Q / Q$ genotype $(\mathrm{OR}=0.76$ [0.55-1.04]), an equivocal effect for the $Q / R$ genotype $(\mathrm{OR}=1.10[0.78-1.55])$, and increased asthma symptoms for the $R / R$ genotype $(\mathrm{OR}=1.34$ [0.85-2.13]) [72]. In addition to genetics, exposure to animals, especially within the farm setting, has shown to play a role in asthma.

\section{Exposure to Microbial Products Growing up on a Farm and Asthma Outcomes}

The environment of a farm is a great example of exposure to all of the microbes and microbial products discussed in this review. Carnes et al. [22] found that high concentrations of endotoxin exposure at homes of people not born on a farm have a risk for the development of asthma $(\mathrm{OR}=1.67,95 \% \mathrm{CI}$ (1.26-2.20), $p=0.05)$, compared to individuals who were born on a farm $(\mathrm{OR}=1.18,95 \% \mathrm{CI}(1.02-1.37), p=0.05)$. In addition, Lampi et al. [12] found that people born on a farm had a higher $\mathrm{FEV}_{1}$, compared to those not raised on a farm. The limitation here is that these participants in the Lampi study could be more physically fit having to do the chores of farm work, compared to people not living on a farm. Prior studies have attributed farm-specific protection from the development of asthma from endotoxin exposed in utero and during early childhood [13, 73, 74].

An older study conducted on Amish and Hutterite communities whom participate in farming activities has revealed two very different results $[75,76]$. The Amish farm children of Indiana were found to have a lower prevalence of asthma and allergen sensitization $(5.2 \%$ vs. $21.3 \%$ and $7.2 \%$ vs. $33.3 \%$, respectively), compared to the Hutterite farm children of South Dakota [75, 76]. The difference between these two farming communities was that the Amish have constant direct contact with animals to do all of their farming traditionally, and the Hutterite community relies on machinery and maintains the animals in one localized area away from the community homes $[75,76]$. This finding brings up a few questions.
Why is early farm exposure to endotoxin related to protective effects against the development of asthma and asthma symptoms; whereas, non-farm house endotoxin exposure is generally associated with asthma and asthma exacerbations? Are there different microbes related to farm animals versus household pets, which are associated with increasing asthma symptoms $[5,31]$ ? In a different study, Tischer et al. [25] examined the German LISAplus birth cohort and found that children who slept on animal fur during the first 3 months of life had higher exposure to endotoxin in their mattress, compared to children who did not sleep on fur. More importantly, the researchers found a decrease in the risk of asthma development by age 6 for children who slept on animal fur during the first 3 months of life $(\mathrm{aOR}=0.56,95 \%, \mathrm{CI}(0.31-1.01)$. In addition, for TNF- $\alpha$, $\mathrm{IL}-2$, and $\mathrm{IL}-4$ producing $\mathrm{T}$ cells, there were no significant changes found in blood levels associated with sleeping on animal fur the first 3 months of life [25].

\section{Conclusion}

This review has shed light on several different findings within the literature. Based on the information provided, sensitization within the non-farming community for bacterial, fungal, and viral products increases with $\operatorname{IgE} \mathrm{Ab}$ expression and over time with age [43, 64, 77]. In terms of the fungal species, Aspergillus fumigatus has shown to induce one of the highest sensitizations for moderate/severe asthma [54, 78]. In addition, human colonization of the genera Cladosporium, Alternaria, and Penicillium have been associated with severe asthma and their ambient environmental concentration is similarly proportional in various parts of the world [41, 45, 53, 56-58]. For viruses, rhinovirus has been shown to be one of the most common triggers of a viral source for an asthma exacerbation $[9,11 \bullet, 15,63,79,80]$. Early exposure to endotoxin at a young age within the farm setting with direct animal contact may reduce the chances of developing asthma later in life $[12,22,75,76]$. For children not living on a farm, growing up with a cat or dog may have a protective effect against asthma symptoms [8•, 24••]. The mechanism of this effect is yet to be understood and it appears that genetics plays a role in asthma severity especially among ethnic minorities [72].

\section{Further Research}

Further research is needed to investigate the difference in microbes between farm animals and household pets and how early exposure effects the human microbiome and the immune system's response to inflammatory triggers. In addition, since studies have shown that people with severe asthma may be colonized with various genus of fungi, it would be worthwhile to further investigate the treatment of moderate/severe 
asthmatics colonized with fungi with other methods not associated with toxic side effects related to current medications for anti-fungals. In addition, more studies are needed examining the mechanism(s) for the transition of bacteria in the microbiome during childhood and how this may effect asthma outcomes. Biomarkers such as dimethylamine, a metabolite produced by bacteria within the gastrointestinal tract, may pose a clue as it has been demonstrated to decrease in concentration from higher to lower levels with the development of asthma in children [81]. Further advances are also being made with dupilumab, a monoclonal antibody that blocks a common receptor for interleukin-4 (IL-4) and interleukin-13 (IL13), involved in type 2 inflammation [82]. In adult patients with atopic asthma, it has been shown to reduce severe asthma exacerbations [82]. This medication has recently been approved for children 12 years old and up for the treatment of severe asthma [83]. Continued exploration of the human microbiome and its interaction with the environment hopefully may lead to more discoveries.

Funding Research reported in this publication is supported by the National Institute of Allergy and Infectious Diseases of the National Institutes of Health (Grant No: K24AI106822)

\section{Compliance with Ethical Standards}

All reported studies/experiments with human subjects performed by the authors have been previously published and compiled with all applicable ethical standards (including the Helsinki declaration and its amendments, institutional/national research committee standards, and international/national/institutional guidelines).

Conflict of Interest The authors declare no conflicts of interest relevant to this manuscript.

Human and Animal Rights and Informed Consent This article does not contain any studies with human or animal subjects performed by any of the authors.

\section{References}

Papers of particular interest, published recently, have been highlighted as:

- Of importance

•- Of major importance

1. CDC. Most Recent National Asthma Data. 2017. Available from: https://www.cdc.gov/asthma/most_recent_national_asthma_data. htm. Accessed 1 Sept 2019.

2. CDC. Asthma. 2019. Available from: https://www.cdc.gov/asthma/ default.htm. Accessed 1 Sept 2019.

3. Nurmagambetov T, Kuwahara R, Garbe P. The economic burden of asthma in the United States, 2008-2013. Ann Am Thorac Soc. 2018;15(3):348-56.

4. Zhang Q, Cox M, Liang Z, Brinkmann F, Cardenas PA, Duff R, et al. Airway microbiota in severe asthma and relationship to asthma severity and phenotypes. PLoS One. 2016;11(4):e0152724.
5. Thorne PS, et al. Endotoxin exposure: predictors and prevalence of associated asthma outcomes in the United States. Am J Respir Crit Care Med. 2015;192(11):1287-97.

6. Masaki K, et al. Characteristics of severe asthma with fungal sensitization. Ann Allergy Asthma Immunol. 2017;119(3):253-7.

7. Longo DL. Harrison's principles of internal medicine. 18th ed. New York: McGraw-Hill Companies; 2011.

8. Tischer $\mathrm{C}$, et al. Early exposure to bio-contaminants and asthma up to 10 years of age: results of the HITEA study. Eur Respir J. 2015;45(2):328-37 This study was able to examine 3 birth cohorts from 3 different cultures and examine the effect of endotoxin, (1,3)- $\beta$-D-glucan, and LPS on each cohort from different geographical regions for the development of asthma in children from birth to age $6[8]$. It has been demonstrated that the climate and geographical region can affect asthma outcomes [14, 25]; and this was observed as high endotoxin levels were associated with asthma at age 6 for the PIAMA cohort (Dutch); an inverse relationship with the INMA cohort (Spanish), and no association with the LISAplus cohort (German). Also, other studies have shown that early constant animal exposure reduces the risk of asthma $[13,24,72,73]$ and this was observed with the INMA cohort, where many of the participants had a dog at home [8]. As there is still controversy whether pets have a protective effect against asthma or the tendency to cause asthma development, this study gives additional clues about the environment that need to be considered.

9. Rubner FJ, Jackson DJ, Evans MD, Gangnon RE, Tisler CJ, Pappas TE, et al. Early life rhinovirus wheezing, allergic sensitization, and asthma risk at adolescence. J Allergy Clin Immunol. 2017;139(2): 501-7.

10. Bonnelykke K, et al. Association between respiratory infections in early life and later asthma is independent of virus type. J Allergy Clin Immunol. 2015;136(1):81-86.e4.

11. Lukkarinen M, et al. Rhinovirus-induced first wheezing episode predicts atopic but not nonatopic asthma at school age. J Allergy Clin Immunol. 2017;140(4):988-95 Previous studies have demonstrated that early infant exposure to human rhinovirus (HRV) is associated with triggering asthma attacks [15, 5557]. However, little was known if exposure to HRV leads to the development of asthma later during childhood. This study demonstrated that early childhood exposure to rhinovirus significantly increased the risk for the development asthma, and found clinical markers that could be used to predict the development of atopic and non-atopic asthma in children [11]. This study was different from previous studies, because it only included a birth cohort of healthy children and no high-risk infants.

12. Lampi J, Koskela H, Hartikainen AL, Ramasamy A, Couto Alves A, Järvelin MR, et al. Farm environment during infancy and lung function at the age of 31 : a prospective birth cohort study in Finland. BMJ Open. 2015;5(7):e007350.

13. Riedler J, Braun-Fahrländer C, Eder W, Schreuer M, Waser M, Maisch S, et al. Exposure to farming in early life and development of asthma and allergy: a cross-sectional survey. Lancet. 2001;358(9288):1129-33.

14. Khan MS, Coulibaly S, Matsumoto T, Yano Y, Miura M, Nagasaka $\mathrm{Y}$, et al. Association of airborne particles, protein, and endotoxin with emergency department visits for asthma in Kyoto, Japan. Environ Health Prev Med. 2018;23(1):41.

15. Zheng SY, Wang LL, Ren L, Luo J, Liao W, Liu EM. Epidemiological analysis and follow-up of human rhinovirus infection in children with asthma exacerbation. J Med Virol. 2018;90(2):219-28.

16. Wang YC, Tsai CS, Yang YH, Huang KY, Hsieh WC, Kuo TY, et al. Association between enterovirus infection and asthma in 
children: a 16-year nationwide population-based cohort study. Pediatr Infect Dis J. 2018;37(9):844-9.

17. Vazquez-Perez JA, et al. EV-D68 infection in children with asthma exacerbation and pneumonia in Mexico City during 2014 autumn. Influenza Other Respir Viruses. 2016;10(3):154-60.

18. Bjerregaard A, et al. High fractional exhaled nitric oxide and sputum eosinophils are associated with an increased risk of future virus-induced exacerbations: a prospective cohort study. Clin Exp Allergy. 2017;47(8):1007-13.

19. Kanchongkittiphon W, Gaffin JM, Phipatanakul W. The indoor environment and inner-city childhood asthma. Asian Pac J Allergy Immunol. 2014;32(2):103-10.

20. Shamsollahi HR, Ghoochani M, Jaafari J, Moosavi A, Sillanpää M, Alimohammadi M. Environmental exposure to endotoxin and its health outcomes: a systematic review. Ecotoxicol Environ Saf. 2019;174:236-44.

21. Lai PS, et al. School Endotoxin Exposure and Asthma Morbidity in Inner-city Children. Chest. 2015;148(5):1251-8.

22. Carnes MU, et al. House dust endotoxin levels are associated with adult asthma in a U.S. farming population. Ann Am Thorac Soc. 2017;14(3):324-31.

23. Biswas SK, Lopez-Collazo E. Endotoxin tolerance: new mechanisms, molecules and clinical significance. Trends Immunol. 2009;30(10):475-87.

24.• O'Connor GT, et al. Early-life home environment and risk of asthma among inner-city children. J Allergy Clin Immunol. 2018;141(4):1468-75 Previous studies have demonstrated that exposure to animals has a protective effect against asthma development $[8,13,24,72,73]$. This study not only demonstrated this concept, following patients from birth to 7 years of age, but also found that the bacterial species Kocuria, Bifidobacterium, Alloiococcus, and Acinobacter are found in the home of children without asthma, but not in the homes of children with asthma [24]. Furthermore, a previous study has demonstrated that the microbiome of infants' nasopharynx is initially colonized with Alloiococcus when healthy and declines with acute respiratory infections and the development of asthma [68]. Thus, this study shows key bacteria may have the potential to suppress or trigger the development of asthma from early childhood exposure.

25. Tischer C, Standl M, Lehmann I, Schaaf B, von Berg A, Heinrich J. Sleeping on animal fur is related to asthma outcomes in later childhood. Eur Respir J. 2015;46(1):107-14.

26. Teo SM, Mok D, Pham K, Kusel M, Serralha M, Troy N, et al. The infant nasopharyngeal microbiome impacts severity of lower respiratory infection and risk of asthma development. Cell Host Microbe. 2015;17(5):704-15.

27. den Hollander WJ, et al. Helicobacter pylori in children with asthmatic conditions at school age, and their mothers. Aliment Pharmacol Ther. 2016;43(8):933-43.

28. Lu S, Hartert TV, Everard ML, Giezek H, Nelsen L, Mehta A, et al. Predictors of asthma following severe respiratory syncytial virus (RSV) bronchiolitis in early childhood. Pediatr Pulmonol. 2016;51(12):1382-92.

29. Homaira N, et al. Association between respiratory syncytial viral disease and the subsequent risk of the first episode of severe asthma in different subgroups of high-risk Australian children: a whole-ofpopulation-based cohort study. BMJ Open. 2017;7(11):e017936.

30. Kitsantas P, Nirmalraj L. Effects of respiratory syncytial virus infection in infancy on asthma and respiratory allergy in 6-year-old children. South Med J. 2018;111(11):698-702.

31. Mendy A, Wilkerson J, Salo PM, Cohn RD, Zeldin DC, Thorne PS. Endotoxin predictors and associated respiratory outcomes differ with climate regions in the U.S. Environ Int. 2018;112:218-26.
32. Mendy A, et al. Exposure and sensitization to pets modify endotoxin association with asthma and wheeze. J Allergy Clin Immunol Pract. 2018;6(6):2006-2013.e4.

33. Delfino RJ, Staimer N, Tjoa T, Gillen DL. Relations of exhaled nitric oxide and FEV1 to personal endotoxin exposure in schoolchildren with asthma. Occup Environ Med. 2015;72(12): $830-6$.

34. Berger M, de Boer JD, Bresser P, van der Poll T, Lutter R, Sterk PJ, et al. Lipopolysaccharide amplifies eosinophilic inflammation after segmental challenge with house dust mite in asthmatics. Allergy. 2015;70(3):257-64.

35. Oluwole O, Rennie DC, Senthilselvan A, Dyck R, Afanasieva A, Kirychuk S, et al. The association between endotoxin and beta-(1$>3$ )-D-glucan in house dust with asthma severity among schoolchildren. Respir Med. 2018;138:38-46.

36. Leung TF, Wong YS, Chan IH, Yung E, Wong CK, Lam CW, et al. Indoor determinants of endotoxin and dust mite exposures in Hong Kong homes with asthmatic children. Int Arch Allergy Immunol. 2010;152(3):279-87.

37. Phipatanakul W, Celedón JC, Raby BA, Litonjua AA, Milton DK, Sredl D, et al. Endotoxin exposure and eczema in the first year of life. Pediatrics. 2004;114(1):13-8.

38. Litonjua AA, et al. A longitudinal analysis of wheezing in young children: the independent effects of early life exposure to house dust endotoxin, allergens, and pets. J Allergy Clin Immunol. 2002;110(5):736-42.

39. Tavernier GO, et al. Endotoxin exposure in asthmatic children and matched healthy controls: results of IPEADAM study. Indoor Air. 2005;15(Suppl 10):25-32.

40. Mendy A, Cohn RD, Thorne PS. Endotoxin exposure, serum vitamin D, asthma and wheeze outcomes. Respir Med. 2016;114:61-6.

41. Vincent M, et al. Relationship between mold exposure, specific IgE sensitization, and clinical asthma: a case-control study. Ann Allergy Asthma Immunol. 2018;121(3):333-9.

42. Tanaka A, et al. Evaluation of the association between sensitization to common inhalant fungi and poor asthma control. Ann Allergy Asthma Immunol. 2016;117(2):163-168.e1.

43. Lehmann S, Sprünken A, Wagner N, Tenbrock K, Ott H. Clinical relevance of IgE-mediated sensitization against the mould Alternaria alternata in children with asthma. Ther Adv Respir Dis. 2017;11(1):30-9.

44. Baxi SN, et al. Association between fungal spore exposure in innercity schools and asthma morbidity. Ann Allergy Asthma Immunol. 2019;122(6):610-615.e1.

45. Oluwole O, Kirychuk SP, Lawson JA, Karunanayake C, Cockcroft DW, Willson PJ, et al. Indoor mold levels and current asthma among school-aged children in Saskatchewan, Canada. Indoor Air. 2017;27(2):311-9.

46. Kim JL, Henneberger PK, Lohman S, Olin AC, Dahlman-Höglund A, Andersson E, et al. Impact of occupational exposures on exacerbation of asthma: a population-based asthma cohort study. BMC Pulm Med. 2016;16(1):148.

47. Medrek SK, et al. Fungal sensitization is associated with increased risk of life-threatening asthma. J Allergy Clin Immunol Pract. 2017;5(4):1025-1031.e2.

48. Cavaleiro Rufo J, Madureira J, Paciência I, Aguiar L, Pereira C, Silva $\mathrm{D}$, et al. Indoor fungal diversity in primary schools may differently influence allergic sensitization and asthma in children. Pediatr Allergy Immunol. 2017;28(4):332-9.

49. Tham R, Katelaris CH, Vicendese D, Dharmage SC, Lowe AJ, Bowatte $\mathrm{G}$, et al. The role of outdoor fungi on asthma hospital admissions in children and adolescents: a 5-year time stratified case-crossover analysis. Environ Res. 2017;154:42-9.

50. Woolnough KF, Richardson M, Newby C, Craner M, Bourne M, Monteiro W, et al. The relationship between biomarkers of fungal 
allergy and lung damage in asthma. Clin Exp Allergy. 2017;47(1): 48-56.

51. Dannemiller KC, et al. Indoor microbial communities: influence on asthma severity in atopic and nonatopic children. J Allergy Clin Immunol. 2016;138(1):76-83.e1.

52. Choi H, Byrne S, Larsen LS, Sigsgaard T, Thorne PS, Larsson L, et al. Residential culturable fungi, (1-3, 1-6)-beta-d-glucan, and ergosterol concentrations in dust are not associated with asthma, rhinitis, or eczema diagnoses in children. Indoor Air. 2014;24(2): 158-70.

53. Carpagnano GE, Malerba M, Lacedonia D, Susca A, Logrieco A, Carone M, et al. Analysis of the fungal microbiome in exhaled breath condensate of patients with asthma. Allergy Asthma Proc. 2016;37(3):41-6.

54. Farrant J, Brice H, Fowler S, Niven R. Fungal sensitisation in severe asthma is associated with the identification of Aspergillus fumigatus in sputum. J Asthma. 2016;53(7):732-5.

55. Segura N, Fraj J, Cubero JL, Sobrevía MT, Lezaun A, Ferrer L, et al. Mould and grass pollen allergy as risk factors for childhood asthma in Zaragoza, Spain. Allergol Immunopathol (Madr). 2016;44(5):455-60.

56. Polyzoi E, Polyzois D. Presence of household mold, children's respiratory health, and school absenteeism: cause for concern. J Environ Health. 2017;79(7):28-35.

57. Mueller-Rompa S, Janke T, Schwaiger K, Mayer M, Bauer J, Genuneit $\mathrm{J}$, et al. Identification of fungal candidates for asthma protection in a large population-based study. Pediatr Allergy Immunol. 2017;28(1):72-8.

58. Tham R, et al. Associations between outdoor fungal spores and childhood and adolescent asthma hospitalizations. J Allergy Clin Immunol. 2017:139(4):1140-1147.e4.

59. Lewis TC, Metitiri EE, Mentz GB, Ren X, Carpenter AR, Goldsmith AM, et al. Influence of viral infection on the relationships between airway cytokines and lung function in asthmatic children. Respir Res. 2018;19(1):228.

60. Bjerregaard A, Laing IA, Poulsen N, Backer V, Sverrild A, Fally M, et al. Characteristics associated with clinical severity and inflammatory phenotype of naturally occurring virus-induced exacerbations of asthma in adults. Respir Med. 2017;123:34-41.

61. Saraya T, Kimura H, Kurai D, Ishii H, Takizawa H. The molecular epidemiology of respiratory viruses associated with asthma attacks: a single-center observational study in Japan. Medicine (Baltimore). 2017;96(42):e8204.

62. Verduyn M, et al. Serum IgG concentrations in adult patients experiencing virus-induced severe asthma exacerbations. J Allergy Clin Immunol Pract. 2019;7(5):1507-1513.e1.

63. Nguyen-Thi-Dieu T, et al. Study of clinical characteristics and cytokine profiles of asthmatic children with rhinovirus infection during acute asthma exacerbation at National Hospital of Pediatrics. Can Respir J. 2018;2018:9375967.

64. Smith-Norowitz TA, et al. Increased seroprevalence of enterovirus $71 \mathrm{IgE}$ antibodies in asthmatic compared with non-asthmatic children. Ir J Med Sci. 2017;186(2):495-503.

65. Itagaki T, Aoki Y, Matoba Y, Tanaka S, Ikeda T, Mizuta K, et al. Clinical characteristics of children infected with enterovirus D68 in an outpatient clinic and the association with bronchial asthma. Infect Dis (Lond). 2018;50(4):303-12.

66. Funakoshi Y, Ito K, Morino S, Kinoshita K, Morikawa Y, Kono T, et al. Enterovirus D68 respiratory infection in a children's hospital in Japan in 2015. Pediatr Int. 2019;61(8):768-76.

67. Yoshii Y, Shimizu K, Morozumi M, Chiba N, Ubukata K, Uruga H, et al. Detection of pathogens by real-time PCR in adult patients with acute exacerbation of bronchial asthma. BMC Pulm Med. 2017; 17(1):150

68. Jaiwong C, Ngamphaiboon J. Effects of inactivated influenza vaccine on respiratory illnesses and asthma-related events in children with mild persistent asthma in Asia. Asian Pac J Allergy Immunol. 2015;33(1):3-7.

69. Goldstein E, Finelli L, O'Halloran A, Liu P, Karaca Z, Steiner CA, et al. Hospitalizations associated with respiratory syncytial virus (RSV) and influenza in children, including children diagnosed with asthma. Epidemiology. 2019;30:918-26.

70. Kljaic-Bukvic B, Blekic M, Aberle N, Curtin JA, Hankinson J, Semic-Jusufagic A, et al. Genetic variants in endotoxin signalling pathway, domestic endotoxin exposure and asthma exacerbations. Pediatr Allergy Immunol. 2014;25(6):552-7.

71. Rosa-Rosa L, Zimmermann N, Bernstein JA, Rothenberg ME, Khurana Hershey GK. The R576 IL-4 receptor alpha allele correlates with asthma severity. J Allergy Clin Immunol. 1999;104(5): 1008-14.

72. Lai PS, et al. Gene-environment interaction between an IL4R variant and school endotoxin exposure contributes to asthma symptoms in inner-city children. J Allergy Clin Immunol. 2018;141(2): 794-796.e3.

73. Douwes J, Cheng S, Travier N, Cohet C, Niesink A, McKenzie J, et al. Farm exposure in utero may protect against asthma, hay fever and eczema. Eur Respir J. 2008;32(3):603-11.

74. Braun-Fahrlander C, et al. Environmental exposure to endotoxin and its relation to asthma in school-age children. N Engl J Med. 2002;347(12):869-77.

75. Holbreich M, Genuneit J, Weber J, Braun-Fahrländer C, Waser M, von Mutius E. Amish children living in northern Indiana have a very low prevalence of allergic sensitization. J Allergy Clin Immunol. 2012;129(6):1671-3.

76. Motika CA, Papachristou C, Abney M, Lester LA, Ober C. Rising prevalence of asthma is sex-specific in a US farming population. J Allergy Clin Immunol. 2011;128(4):774-9.

77. Song WJ, Sintobin I, Sohn KH, Kang MG, Park HK, Jo EJ, et al. Staphylococcal enterotoxin IgE sensitization in late-onset severe eosinophilic asthma in the elderly. Clin Exp Allergy. 2016;46(3): 411-21.

78. Chopra V, et al. Correlation of aspergillus skin hypersensitivity with the duration and severity of asthma. Monaldi Arch Chest Dis. 2017;87(3):826.

79. Tovey ER, et al. Rhinoviruses significantly affect day-to-day respiratory symptoms of children with asthma. J Allergy Clin Immunol. 2015;135(3):663-9.e12.

80. Stelzer-Braid S, Tovey ER, Willenborg CM, Toelle BG, Ampon R, Garden FL, et al. Absence of back to school peaks in human rhinovirus detections and respiratory symptoms in a cohort of children with asthma. J Med Virol. 2016;88(4):578-87.

81. Chiu CY, et al. Longitudinal urinary metabolomic profiling reveals metabolites for asthma development in early childhood. Pediatr Allergy Immunol. 2018;29(5):496-503.

82. Corren, J, et al. Dupilumab efficacy in patients with uncontrolled, moderate-to-severe allergic asthma. J Allergy Clin Immunol Pract. 2019. https://doi.org/10.1016/j.jaip.2019.08.050.

83. Licari A, Manti S, Castagnoli R, Parisi GF, Salpietro C, Leonardi S, et al. Targeted therapy for severe asthma in children and adolescents: current and future perspectives. Paediatr Drugs. 2019;21(4): 215-37.

Publisher's Note Springer Nature remains neutral with regard to jurisdictional claims in published maps and institutional affiliations. 